\title{
EL PAPEL DE LA MUJER EN EL FRANQUISMO Y EN LA DEMOCRACIA. ANÁLISIS COMPARATIVO ENTRE ÉPOCAS
}

Ma Pilar Garrido Cárdenas, Mª Lina Higueras Rodríguez. Universidad de Granada

\section{Resumen}

El papel de la mujer en España ha ido cambiando de una manera significativa a lo largo del siglo XX, sobre todo precedido por los cambios históricos que han ido sucediendo en este país durante dicho período. Nuestro trabajo se centra en la comparación entre dos épocas que han sido muy significativas en España como son el franquismo y la democracia. En estos períodos se pueden ver claramente el cambio del papel de la mujer con respecto a la sociedad. Se ha analizado para ello varios libros y manuales de distintas editoriales y autores de ambas épocas para proceder a un análisis comparativo. Las conclusiones nos llevan a afirmar que el papel de la mujer ha sido reconocido durante el período de la transición, ya que como se ha podido comprobar el papel de la misma durante el régimen franquista, era secundario y estaba ligado siempre a la figura del hombre.

Palabras Clave: Igualdad de oportunidades, Democracia, Libro de texto, Estereotipos.

\section{Introducción}

La igualdad de los derechos y deberes entre los ciudadanos es básica para un libre desarrollo personal basado en la equidad. Gracias a esto, la mujer puede introducirse en la sociedad con las mismas oportunidades que los hombres. Estos aspectos son tan básicos para el desarrollo de la sociedad, que aparecen reflejados en las leyes universales como por ejemplo la Declaración Universal de los Derechos Humanos.

La Declaración Universal de los Derechos Humanos adoptada por las Naciones Unidas en 1948, reúne que todos los derechos son considerados básicos para todas las personas. Los Derechos Humanos son considerados como las facultades, libertades y reivindicaciones inherentes a cada persona por el solo hecho de su condición humana. Esto quiere decir que se trata de derechos inalienables (nadie, bajo ningún concepto, puede privar de estos derechos a otro sujeto más allá del orden jurídico existente) e independientes de cualquier factor particular (raza, nacionalidad, religión, sexo, etc.).

En contraste con la actual legislación, nos encontramos con una serie de fueros y leyes proclamados por el dictador Francisco Franco, en los cuales excluía a la mujer de todo tipo de actividades, con el fin de mantenerlas en un papel sumiso donde eran las encargadas del mantenimiento de la casa y del cuidado de sus hijos. Como podemos comprobar, existían diferentes revistas donde se mostraban los pasos que debía de seguir una mujer para cumplir su rol: sumisión, estar guapa para el marido, saber comportarse, así como complacerlos en todo.

Durante el tiempo que duró la dictadura, a las mujeres se les fueron suprimiendo todos los derechos que habían conseguido con la constitución promulgada en 1931, en la cual a la mujer se le había otorgado un papel igualitario con respecto al hombre, así como el derecho al voto. Uno de los primeros fueros promulgados fue el de Trabajo en 
1938, donde a las mujeres casadas se les negaba el derecho al mercado laboral. Únicamente, podían trabajar las mujeres solteras o viudas sometidas a los varones.

Estas leyes se mantuvieron vigentes hasta 1976 con la Ley de las Relaciones Laborales, ya que con la muerte de Franco y el fin de la dictadura, surgió un gran avance en el papel que desempeñaba la mujer dentro de la sociedad. Según la Declaración Universal de Derechos Humanos dice que "cualquier persona puede prevalerse de todos los derechos y libertades proclamados en la presente Declaración sin distinción de sexo..."

El derecho de la mujer a no ser discriminada expone principios de igualdad de derechos y respeto de la dignidad humana. Lo que se pretende con esto, es que la mujer en las mismas condiciones que el hombre, participe en la vida política, social, económica, y cultural, lo cual constituye un elemento para el aumento del bienestar de la sociedad.

Existen muchos estudios sobre el papel de la mujer en la época franquista. La Sección Femenina desempeñaba un importante papel asistencial y educativo, difundiendo entre las mujeres normas de higiene y de puericultura y diversos oficios, por medio del Servicio Social, teóricamente obligatorio. También rescataba el folclore de todas las regiones, en trance de perderse por las modas modernas. Su máxima dirigente, Pilar Primo de Rivera, indicaba en una circular, apenas terminada la guerra, que "las mujeres van a ser más limpias, los niños más sanos, los pueblos más alegres y las casas más claras". Declaradamente anti feminista, la Sección Femenina propugnaba para la mujer el deporte, la profesionalización y la entrada en la universidad, tratando de hacerlo compatible con su función de madre y ama de casa. Creó Escuelas de Hogar, centros de divulgación sanitaria, cátedras ambulantes, etc. (Moa, 2007)

En la actualidad, numerosos autores afirman que no hemos logrado aún una equidad total en los roles entre hombres y mujeres. La actualidad en España adolece, como otros países de Europa y Norteamérica, de una reacción negativa contra el feminismo y la percepción errónea de que las mujeres han logrado la igualdad. (Cruz y Zecchi, 2004)

Si nos ubicamos en los actuales libros de texto, se puede observar un gran cambio con respecto a los publicados en la época franquista, ya que en la actualidad se centran mucho más en la definición de igualdad y equidad como se comprobará más adelante.

\section{Análisis comparativo de los libros de texto en ambas épocas}

Para el estudio comparativo entre ambas épocas se procedió a analizar varios libros y manuales de texto procedentes de uno y otro período. Los libros donde se pueden observar las diferencias más notorias en el rol de la mujer son, con respecto a la época franquista: La española cuando besa (Otero, 1999), Convivencia social (Werner, C. 1958) y Nociones de urbanidad para niñas (Pascual, 1937). Con respecto a la época que concierna a la Democracia, se hace referencia a libros de texto de distintas asignaturas y de distintas editoriales como son Educación para la ciudadanía (VVAA, Ed. Everest y Ed. laberinto), Lengua y Literatura (VVAA, Ed. Guadiel) e Historia y ciencias sociales (VVAA, Ed. Anaya) 
En primer lugar, se comprueba que se ha avanzado mucho en el trato igualitario hacia la mujer. La primera diferencia que se encuentra entre varias épocas es que tan solo en la portada de los libros analizados se puede observar que existe desde un principio el papel marginal de la mujer, por ejemplo el libro de "la española cuando besa" (Otero, 1999) muestra desde un principio lo que se trata en el libro, que son por ejemplo, actitudes y comportamientos que tiene que tener la mujer frente al hombre. Sin embargo, en los libros de la época actual, se observa cómo se pretende concienciar a la sociedad de hoy en día, que tanto la mujer como el hombre poseen los mismos derechos e igualdades en la sociedad. Un ejemplo de ello son los libros de educación para la ciudadanía, pues a partir del título se puede observar como la sociedad ha ido cambiando y como se debe de educar en igualdad.

En segundo lugar, se observa que los libros de la etapa franquista están divididos por lecciones, las cuales las niñas tenían que ir aprendiendo para comportarse de forma correcta según las condiciones de esta etapa. Sin embargo, en los libros actuales se fomenta la transversalidad a lo largo de todas las unidades didácticas aunque no se esté tratando de una forma directa el tema de la igualdad de oportunidades entre hombres y mujeres.

En tercer lugar, se encuentra otra diferencia en lo que respecta a las imágenes de los libros, pues en los manuales de la época franquista, se representa a la mujer como el ideal de familia, cuidando a la familia y realizando sus labores como ama de casa. Además en los pies de foto se utiliza la ironía, mostrando algún hombre haciendo las tareas de casa, cuidando a los niños, mujeres haciendo deporte, etc., mientras que en la etapa actual se puede observar hombres realizando las tareas que antiguamente sólo realizaban las mujeres, como por ejemplo planchar, limpiar, cocinar, etc. así como también, aparecen las mujeres ejerciendo trabajos propios del hombre como albañil, carpintera, informática, presidenta, etc.

Por último, en el lenguaje se halla desigualdad en la forma de expresión de ambas etapas. En la época franquista, los libros muestran un lenguaje estricto y severo, mostrándose en algunas ocasiones cómo las niñas debían de hablar a los mayores como si fuesen superiores, dirigiéndose a ellos por "usted" y hablándoles con mucho respeto. Sin embargo, los libros actuales no existen lenguaje discriminatorio ni sexista, tratando por igual tanto al hombre como a la mujer.

\section{Discusión tras el análisis}

El avance en el papel de la mujer a lo largo de estas décadas de democracia, ha sido más que notorio, ya que como se comprueba, en los libros de texto antiguos existía una gran diferenciación entre los manuales que estaban destinados para las mujeres y para los hombres, así como un lenguaje sexista en el que se daba importancia a la superioridad del hombre, dejando la figura de la mujer en un segundo plano.

Las imágenes que aparecían en estos manuales nos muestran al hombre como alguien luchador, valiente y fuerte que debía ser el encargado de sacar el país adelante. Mientras que la mujer aparecía en muchas fotos de espalda, o directamente no aparecía. Cuando lo hacía, siempre era acompañada de un hombre o realizando tareas del hogar, así como en el cuidado de sus hijos. En los libros de texto de la actualidad, sin embargo, se observa una gran evolución en el papel de la mujer. Aparecen por fin realizando tareas que antes estaban únicamente destinadas a los hombres, como por ejemplo, trabajos técnicos, estudios, tareas de bricolaje etc. 
Aunque este avance no es tan notorio como debería ser, ya que no en todas las materias aparece esta igualdad en el mismo grado, por lo que se puede afirmar que aún queda un largo camino por recorrer en el tema de la igualdad entre hombres y mujeres. En nuestra sociedad existe una serie de estereotipos falsos sobre la mujer, debido a que a lo largo de la historia, durante las guerras o en periodos de crisis, las mujeres han tenido un papel secundario en la sociedad de manera general y en el mundo del trabajo en particular. Desde los años veinte del pasado siglo, la mujer, poco a poco se ha ido introduciendo en la sociedad hasta ser un papel esencial en ésta. Pero en España, este avance, no se sucedió hasta la entrada de la democracia en el país, avanzando hacia la adquisición de una igualdad en el mundo cultural, jurídico y laboral con respecto al hombre. A pesar de todo esto, las mujeres saben que son capaces de valerse por ellas mismas, sin estar subordinadas a un hombre, y que existe una vida más allá de las tareas domésticas y del cuidado de los hijos.

\section{Referencias}

Arrufat, M. Grané, M. y Goméz, S (2002) Lengua y literatura. Ed. Guadiel. Barcelona. Baig, A.; Codina, S. (2007) Educación para la ciudadanía y los derechos humanos. Ed. Teide: Barcelona.

Bellido Cruz, L.; García Martín, S.; García Peña, J. (2007) Educación para la ciudadanía. Ed. Everest: León.

Burgos, M. Calvo, J. Jaramillo, M. Martín, S. (2006) Historia y ciencias sociales. ed. Anaya: Madrid.

Cruz, J y Zecchi, B (2004). La mujer en la España actual: ¿evolución o involución?. Ed. Icaria: Barcelona

Enciclopedia escolar en dibujos. Grado elemental (1945). Ed. Afrodísio Aguado: Madrid

Moreno, M. (1986) Cómo se enseña a ser niña: el sexismo en la escuela. Ed. Icaria: Barcelona.

Moa, P (2007) Años de hierro. ed. La esfera de los libros: Madrid.

Navarro Sustaeta, P.; Díaz Martínez, C. (2007) Educación para la ciudadanía. Madrid. Ed. Anaya.

Otero, L (1998) Mi mamá me mima. Ed. Plaza et Janés: Barcelona.

Otero, L (1999) La sección femenina. De cuando a la mujer española se le pedía ser hogareña, patriota, obediente, disciplinada, abnegada, diligente, religiosa, decidida, alegre, sufrida y leal. Ed. EDAF, S.A: Madrid

Otero, L (1999) La española cuando besa. Ed. Plaza et Janés: Barcelona.

Pascual, P. (1937) Nociones de urbanidad para las niñas. Ed. Hijos de Paluzíe: Barcelona. 
Perea Rodríguez, J; Gómez Rodríguez, E. Pagés Blanch, J. Muñoz García, F. (2007) Educación para la ciudadanía y los derechos humanos. Madrid. E. Laberinto.

Pérez Carrasco, J. Díaz Otero, C. Díaz Fleitas, J.M. (2007) Jóvenes ciudadanos. Educación para la ciudadanía y los derechos humanos. Ed. Pearson. Madrid.

Sánchez, D y Medina, R. (2007) Educación para la ciudadanía y los derechos humanos. Ed. Algaida: Sevilla

Serrano, A. (1952) Yo soy español. Ed. Escuela española: Madrid.

Werner, C. (1958) Convivencia social. Ed. Sección femenina: Madrid.

Villegas, S; Barranco, L y Fernández, J (2007) Educación para la ciudadanía. Ed Bruño: Madrid. 